\title{
Correlation of Serum Vaspin, Omentin-1, and adiponectin with metabolic phenotypes in Type-2 diabetes mellitus patients
}

\author{
Mukhtiar Baig', Zohair J Gazzaz², \\ Marwan A Bakarman 3 , Sami H Alzahrani ${ }^{4}$
}

\begin{abstract}
Objectives: To investigate adipocytokines' (vaspin, omentin-1, and adiponectin) correlation with metabolic phenotypes in type 2 diabetes mellitus (T2DM) patients.

Methods: This case-control research was done at the Diabetic Clinic in Jeddah, Kingdom of Saudi Arabia (KSA), from November 2018 to March 2019. Seventy-five T2DM patients and 75 gender, age, and BMImatched healthy subjects were recruited for this research.

Results: In DM patients, the concentrations of serum vaspin and omentin-1 were substantially lower $(p<0.001)$ than in the control group. A significant positive relationship between vaspin concentration and DBP $(p<0.001), B M I(p<0.001)$, and waist circumference $(p<0.001)$ was found in patients and control subjects, while FPG $(p<0.016)$, serum insulin $(p<0.001)$, HOMA-IR $(p<0.001)$, TC $(p<0.001)$, TG $(p<0.001)$, and LDLc $(p<0.001)$ were significantly interrelated among patients. Serum concentrations of omentin-1 and ADN were significantly negatively correlated with serum insulin, HOMA-IR, and TG among the DM group. Serum vaspin and ADN levels were significantly higher in the cases and control groups with $B M I>25$, and no gender-wise variance was observed in adipocytokines levels. Binary logistic regression analysis showed a significantly negative predictive relationship of vaspin and omentin-1 with DM.

Conclusion: The DM group displayed substantially lower serum vaspin and omentin-1 levels. However, there was no consistent relationship observed between these adipocytokines and metabolic phenotypes.
\end{abstract}

KEYWORDS: Diabetes Mellitus; Adipokines; Vaspin; Omentin-1; Adiponectin.

doi: https://doi.org/10.12669/pjms.37.7.4330

How to cite this:

Baig M, Gazzaz ZJ, Bakarman MA, Alzahrani SH. Correlation of Serum Vaspin, Omentin-1, and adiponectin with metabolic phenotypes in Type-2 diabetes mellitus patients. Pak J Med Sci. 2021;37(7):1762-1767. doi: https://doi.org/10.12669/pjms.37.7.4330

This is an Open Access article distributed under the terms of the Creative Commons Attribution License (http://creativecommons.org/licenses/by/3.0), which permits unrestricted use, distribution, and reproduction in any medium, provided the original work is properly cited.

1. Dr. Mukhtiar Baig, Ph.D.

Department of Clinical Biochemistry,

2. Dr. Zohair J Gazzaz, Ph.D.

Department of Internal Medicine,

3. Dr. Marwan A Bakarman, FFCM.

Department of Family and Community Medicine,

4. Dr. Sami H Alzahrani, SBFM

Department of Family Medicine, Faculty of Medicine,

King Abdulaziz University, Jeddah, Saudi Arabia.

1-3: Faculty of Medicine, Rabigh, King Abdulaziz University, Jeddah, Saudi Arabia.

Correspondence:

Dr. Mukhtiar Baig

Department of Clinical Biochemistry,

Faculty of Medicine, Rabigh,

King Abdulaziz University,

Jeddah-22431, Saudi Arabia.

E-mail: drmukhtiarbaig@yahoo.com

* Received for Publication:

February 24, 2021

* Revision Received:

* Revision Accepted:

May 29, 2021

June 15, 2021

\section{INTRODUCTION}

In the recent two decades, diabetes mellitus has doubled worldwide; therefore, it has become an essential challenge to public health. T2DM is a common endocrinological problem in KSA. A recent statement by the World Health Organization described that DM prevalence in the adult population is about $8.5 \%$ (422 million adults), while in KSA, its prevalence is about $14.4 \%{ }^{1}$ All these three factors have an influential function in the occurrence of metabolic syndrome (MetS) and further progression to T2DM. A Saudi study stated $25.4 \%$ and $25.5 \%$ of people were diabetes and had impaired FPG, respectively. ${ }^{2}$

Adiponectin (ADN) is an adipose-specific adipokine that induces the insulin-sensitizer

$\begin{array}{lllll}\text { Pak J Med Sci } \quad \text { November - December } 2021 & \text { Vol. } 37 & \text { No. } 7 & \text { www.pjms.org.pk } 1762\end{array}$ 
effect. Among obese patients, ADN level is usually low, and giving it to obese subjects has reported an increase in insulin sensitivity. ${ }^{3}$ Adiponectin deficiency causes increased insulin resistance, while ADN over-expression leads to enhanced insulin sensitivity and glucose tolerance. ${ }^{4}$ Another adipocytokine known as Vaspin (visceral adipose tissue-derived serine protease inhibitor) has been potentially reported to have an insulin-sensitizer effect, and its gene expression is linked with obesity and MetS. ${ }^{5}$ Moreover, in the adipocyte-insulin axis, vaspin has been reported to play a part among T2DM patients having insulin resistance and those that are obese as well. Thus, vaspin can be associated with the metabolism of glucose and might substantially improve glucose tolerance and insulin sensitivity in patients. ${ }^{6}$ Levels of omentin-1 in plasma have been inversely correlated to BMI and waist circumference, fasting plasma insulin, and insulin sensitivity, ADN, and HDLc., 78 Omentin-1 has been associated with enhancing insulin-mediated phosphorylation leading to the uptake of glucose and inhibiting TNF-a. ${ }^{9}$ This shows that omentin-1, like ADN, might be a protective adipokine.

In the literature, several adipokines have been implicated in the progression of DM. However, a disagreement in the literature is found regarding the involvement of serum omentin-1, vaspin, and ADN in T2DM and their relationship with a metabolic phenotype. So, we planned this study to find out their link with T2DM in a local population sample. The research objective was to identify the correlation of serum vaspin, omentin-1, and ADN with metabolic phenotype among T2DM patients.

\section{METHODS}

This case-control research was performed at the Diabetic Clinic of a Primary Health Care Centre in Jeddah, KSA, from November 2018 to March 2019. Ethical approval was acquired from the Rabigh Faculty of Medicine-Research Ethics Review Committee Approval (No. RMC-01-37-H, dated 26 December, 2016) before the study's start, and written consent was taken from all study participants. The blood sample and other data were collected from 75 adults (37 males and 38 females) with T2DM patients (age ranges from 40-60 years) and 75 healthy adult subjects ( 37 males and 38 females), comparable in gender, age, and BMI with patients. The control group was selected from the general population.

Subjects suffering from liver disease, chronic inflammatory disease, chronic kidney disease, or taking medications that could affect adipocytokines levels wereexcluded from the study. A proforma was filled regarding sociodemographic characteristics, and complete physical examination findings were recorded.

Height and weight were measured in meters and kilograms, respectively, and BMI was determined using the formula, and hip and waist circumference was also measured. HOMA-IR was approximated as "glucose $\left(\mathrm{mmol} / \mathrm{l}^{*}\right.$ insulin $(\mathrm{uU} / \mathrm{ml})$, all divided by 22.5$) " .{ }^{10}$ For blood workup, a sample of five $\mathrm{ml}$ of venous blood in fasting was collected, and serum was stored for outcome parameters analysis. FPG, $\mathrm{HbA} 1 \mathrm{c}$, and lipid profile were determined in

Table-I: General characteristics' comparison of study groups.

\begin{tabular}{|c|c|c|c|}
\hline \multirow{2}{*}{ Parameters } & $\begin{array}{l}\text { Control group } \\
\qquad N=75\end{array}$ & $\begin{array}{c}\text { DM patients } \\
N=75\end{array}$ & \multirow{2}{*}{ P-value } \\
\hline & Mean (SD) & Mean (SD) & \\
\hline Age (yrs) & $54.15 \pm 6.06$ & $53.16 \pm 8.74$ & 0.871 \\
\hline $\begin{array}{l}\text { BP Systolic } \\
\text { (mm Hg) }\end{array}$ & $125.92 \pm 10.13$ & $139.25 \pm 17.41$ & 0.000 \\
\hline $\begin{array}{l}\text { BP Diastolic } \\
(\mathrm{mm} \mathrm{Hg})\end{array}$ & $80.11 \pm 9.31$ & $85.79 \pm 10.75$ & 0.000 \\
\hline $\mathrm{BMI}\left(\mathrm{Kg} / \mathrm{m}^{2}\right)$ & $28.46 \pm 4.02$ & $29.76 \pm 4.51$ & 0.078 \\
\hline $\begin{array}{l}\text { Waist circumf } \\
\text { (in) }\end{array}$ & $36.22 \pm 5.07$ & $38.61 \pm 5.74$ & 0.011 \\
\hline $\mathrm{FPG}(\mathrm{mmol} / \mathrm{L})$ & $5.07 \pm 0.26$ & $8.12 \pm 1.57$ & 0.000 \\
\hline $\begin{array}{l}\text { Serum Insulin } \\
(\mathrm{mIU} / \mathrm{ml})\end{array}$ & $7.98 \pm 2.83$ & $17.43 \pm 4.52$ & 0.000 \\
\hline HOMAIR & $1.80 \pm 0.63$ & $6.30 \pm 2.13$ & 0.000 \\
\hline $\mathrm{TC}(\mathrm{mmol} / \mathrm{l})$ & $3.94 \pm 0.77$ & $4.82 \pm 0.89$ & 0.000 \\
\hline TG (mmol/l) & $1.53 \pm 0.67$ & $1.83 \pm 0.73$ & 0.012 \\
\hline HDLc (mmol/l) & $1.13 \pm 0.41$ & $1.15 \pm 0.19$ & 0.835 \\
\hline LDLc (mmol/l) & $2.75 \pm 0.66$ & $3.20 \pm 0.69$ & 0.003 \\
\hline Vaspin (pg/ml) & $336.92 \pm 58.51$ & $260.30 \pm 75.64$ & 0.000 \\
\hline $\begin{array}{l}\text { Omentin-1 } \\
\text { (ng/ml) }\end{array}$ & $255.75 \pm 58.15$ & $179.17 \pm 62.25$ & 0.000 \\
\hline $\begin{array}{l}\text { Adiponectin } \\
\text { (ug/ml) }\end{array}$ & $3.74 \pm 0.78$ & $3.58 \pm 0.98$ & 0.32 \\
\hline
\end{tabular}

"BMI= Body mass index, FPG=Fasting plasma glucose, $\mathrm{TC}=$ Total cholesterol, $\mathrm{TG}=$ Triglycerides, LDLc $=$ Low density lipoprotein cholesterol, HDLc = High-density lipoprotein cholesterol". 
the King Abdulaziz University, Hospital on autoanalyzer. Human ELISA kits were utilized for measuring vaspin, omentin-1, ADN, and insulin levels.

SPSS version 26.0 was utilized for the data analysis. Quantitative data were reported as mean and standard deviation. Independent T-test was applied for detecting significance between the groups. Pearsons' correlations were utilized to determine the correlation of adipocytokines with other variables. Logistic regression analysis was done to establish the association of study variables with DM. A relevant $p$-value of $<0.05$ was counted significant.

\section{RESULTS}

In DM patients, the concentrations of serum vaspin and omentin- 1 were substantially lower $(p<0.001)$, while no extensive variation in serum ADN levels was noted compared to the control group. The other baseline attributes of the participants are represented in Table-I.

A notable positive correlation was detected between levels of serum vaspin and DBP $(p<0.001)$,
BMI $(p<0.001)$, and waist circumference $(p<0.001)$ in patients and control subjects. At the same time FPG $(\mathrm{p}<0.016)$, serum insulin $(\mathrm{p}<0.001)$, HOMAIR $(p<0.001)$, TC $(p<0.001)$, TG $(p<0.001)$, and LDLc $(p<0.001)$ were significantly correlated among patients only. Serum vaspin levels were inversely associated with omentin and positively linked with ADN among both groups (Table II). Serum omentin-1 had negative correlation with BMI among the control group and negatively related to waist circumference among both groups. A significant negative correlation of ADN and serum omentin-1 concentrations with serum insulin, HOMA-IR, and TG among the DM group was observed (Table II). Serum ADN was significantly correlated with DBP, BMI, and waist circumference in patients and the control group (Table-II).

The BMI-wise comparison displayed that serum levels of ADN and vaspin were substantially higher in the cases and control groups with BMI $>25$. No gender-wise difference was found in adipocytokines levels [not shown in the table].

Table-II: Serum vaspin, omentin, and adiponectin levels relationship with biochemical and clinical parameters.

\begin{tabular}{|c|c|c|c|c|c|c|}
\hline \multirow{3}{*}{ Variables } & \multicolumn{2}{|c|}{ Vaspin $(p g / m l)$} & \multicolumn{2}{|c|}{ Omentin-1 (ng/ml) } & \multicolumn{2}{|c|}{ Adiponectin $(n g / m l)$} \\
\hline & $\begin{array}{c}\text { Control } \\
(n=75)\end{array}$ & $\begin{array}{c}\text { Patients } \\
(n=75)\end{array}$ & Control $n=75$ ) & $\begin{array}{c}\text { Patients } \\
(n=75)\end{array}$ & $\begin{array}{c}\text { Control } \\
n=75)\end{array}$ & $\begin{array}{c}\text { Patients } \\
(n=75)\end{array}$ \\
\hline & $r(P$-value $)$ & $r(P$-value $)$ & $r(P$-value $)$ & $r(P$-value $)$ & $r(P$-value $)$ & $r(P$-value $)$ \\
\hline Age & $-0.03(0.824)$ & $-0.03(0.73)$ & $0.03(0.793)$ & $0.03(0.712)$ & $-0.31(0.000)$ & $-0.01(0.69)$ \\
\hline Systolic BP & $0.44(0.001)$ & $0.08(0.32)$ & $-0.16(0.255)$ & $0.15(0.124)$ & $0.40(.003)$ & $0.09(.28)$ \\
\hline Diastolic BP & $0.44(0.001)$ & $0.36(0.000)$ & $-0.16(0.132)$ & $-0.124(0.167)$ & $0.41(.004)$ & $0.33(.000)$ \\
\hline BMI & $0.70(0.000)$ & $0.67(0.000)$ & $-0.42(0.002)$ & $-0.06(0.505)$ & $0.68(0.000)$ & $0.58(0.000)$ \\
\hline Waist circumference & $0.31(0.02)$ & $0.50(0.000)$ & $-0.33(0.016)$ & $-0.24(0.007)$ & $0.51(0.000)$ & $0.30(0.032)$ \\
\hline FPG & $0.10(0.45)$ & $0.21(0.016)$ & $0.04(0.745)$ & $-0.06(0.505)$ & $0.10(0.25)$ & $0.11(0.22)$ \\
\hline Serum Insulin & $0.07(0.61)$ & $0.49(0.000)$ & $-0.02(0.865)$ & $-0.24(0.007)$ & $0.53(0.000)$ & $-0.01(0.90)$ \\
\hline HOMA-IR & $0.08(0.572)$ & $0.51(0.000)$ & $-0.01(0.946)$ & $-0.21(0.016)$ & $0.46(0.000)$ & $0.01(0.99)$ \\
\hline $\mathrm{TC}$ & $0.07(0.62)$ & $0.34(0.000)$ & $-0.11(0.436)$ & $-0.06(0.486)$ & $0.13(0.14)$ & $0.09(0.53)$ \\
\hline TG & $0.09(0.51)$ & $0.30(0.001)$ & $-0.12(0.377)$ & $-0.26(0.003)$ & $0.20(0.02)$ & $0.15(0.27)$ \\
\hline HDLc & $0.09(0.53)$ & $0.04(0.59)$ & $-0.14(0.325)$ & $0.04(0.629)$ & $0.10(0.265)$ & $-0.08(0.55)$ \\
\hline LDLc & $-0.02(0.87)$ & $0.31(0.000)$ & $0.05(0.707)$ & $0.01(0.907)$ & $0.14(0.11)$ & $0.03(0.81)$ \\
\hline Omentin-1 & $-0.57(0.000)$ & $-0.20(0.02)$ & 1 & 1 & $0.14(0.12)$ & $0.02(0.85)$ \\
\hline Adiponectin & $0.46(0.001)$ & $0.48(0.000)$ & $0.02(0.85)$ & $0.14(0.11)$ & 1 & 1 \\
\hline
\end{tabular}


Mukhtiar Baig et al.

Table- III: Association of study variables with DM (Binary logistics regression analysis)*.

\begin{tabular}{lcccccccc}
\hline \multirow{2}{*}{ Variables } & & & & & & \multicolumn{2}{c}{$95 \%$ C.I. for Exp $(B)$} \\
\cline { 6 - 8 } & & S.E. & Wald $x^{2}$ & $d f$ & Sig. & Exp $(B)$ & Lower & Upper \\
\hline BP Systolic & 0.006 & 0.015 & 0.13 & 1 & 0.710 & 1.006 & 0.976 & 1.036 \\
BP Diastolic & 0.061 & 0.058 & 1.10 & 1 & 0.294 & 1.063 & 0.948 & 1.191 \\
BMI & -0.046 & 0.106 & 0.185 & 1 & 0.667 & 0.955 & 0.776 & 1.176 \\
Waist circumf & 0.011 & 0.086 & 0.017 & 1 & 0.898 & 1.011 & 0.855 & 1.196 \\
FPG & 1.511 & 1.118 & 1.829 & 1 & 0.176 & 4.533 & 0.507 & 40.526 \\
Serum Insulin & -0.129 & 0.385 & 0.112 & 1 & 0.738 & 0.879 & 0.414 & 1.868 \\
HOMAIR & -0.485 & 1.552 & 0.09 & 1 & 0.755 & 0.616 & 0.029 & 12.897 \\
TC & 0.374 & 0.362 & 1.06 & 1 & 0.302 & 1.453 & 0.715 & 2.956 \\
TG & 2.411 & .563 & 18.36 & 1 & .000 & 11.144 & 3.700 & 33.568 \\
HDLc & -1.652 & 1.503 & 1.20 & 1 & 0.272 & 0.192 & 0.010 & 3.643 \\
LDLc & 1.027 & .446 & 5.30 & 1 & 0.021 & 2.792 & 1.165 & 6.690 \\
Vaspin & -0.014 & 0.006 & 6.14 & 1 & 0.013 & 0.986 & 0.974 & 0.997 \\
Omentin & -0.012 & 0.005 & 5.18 & 1 & 0.023 & 0.988 & 0.979 & 0.998 \\
Adiponectin & 0.437 & 0.389 & 1.26 & 1 & 0.262 & 1.547 & 0.722 & 3.316 \\
\hline
\end{tabular}

*Parameters were analyzed to calculate the odds ratio in cases as compared to controls.

Binary logistic regression analysis showed a significantly negative predictive relationship of vaspin and omentin-1 with DM (Table III).

\section{DISCUSSION}

Our study detected significantly lower serum omentin-1 concentrations, and it was inversely correlated with vaspin and no correlation with ADN among both groups. Lower serum omentin-1 was noted in the cases and control groups with $>25$ BMI, but this disparity was not noteworthy, and no gender-wise difference was found. Our study results are comparable with several investigations that described lower omentin-1 levels among T2DM. ${ }^{11,12}$ Literature indicates conflicting results such as a significant positive relationship between serum omentin- 1 and BMI and body fat $\%{ }^{13}$, a significant negative correlation with BMI, HbA1c, CRP, TC, LDLc, and TG, and notable positive relationship with HDL. ${ }^{12}$ A study described no significant link between omentin-1 and lipid profile, FPG, plasma insulin, and hs-CRP ${ }^{14}$, while another research observed its positive association with $\mathrm{HbA} 1 \mathrm{c}$ and negative correlation with BMI, waist circumference, glucose, insulin, HOMA-IR, HDL, TG, DBP, and SBP. ${ }^{15}$
Similar to our results, two studies reported no change in levels of serum omentin- 1 among lean and obese subjects in both groups ${ }^{15,16}$, and comparable to our results a meta-analysis stated a significant connection between DM and omentin-1.. ${ }^{12}$ The declined concentration of serum omentin-1 in T2DM subjects indicates it is important for glucose metabolism. It has been reported that omentin-1 upsurges the transduction of insulin signals by triggering the protein kinase $\mathrm{B}$ and augments the entrance of insulin-facilitated glucose into adipocytes. ${ }^{17}$ It is suggested in the literature that lowered serum omentin-1 concentration affects insulin-mediated glucose entry. ${ }^{18,19}$ Different sample sizes and patients with co-morbidities acting as a confounding factor might have been reasons for inconsistent reported results.

Notably, lower serum vaspin was observed in the DM subjects compared to the control group, and it was inversely correlated with omentin and positively correlated with ADN among both groups. Various metabolic phenotypes were related to serum vaspin levels in patients and control subjects. The higher serum vaspin levels were noted in the subjects with BMI $>25$ in both groups. In binary logistic regression analysis, serum vaspin 
was found to be associated with DM. Several studies found vaspin levels lower ${ }^{20,21}$ and higher ${ }^{22,23}$ in diabetic patients than in the healthy group.

Feng et al. (2014) also described higher vaspin concentrations in obese subjects than in the control group..$^{24}$ On the contrary, no relationship between the vaspin level and obesity was demonstrated. ${ }^{15}$ A study in mice reported improvement in insulin sensitivity and glucose tolerance and after injection of vaspin..$^{25}$ This shows that vaspin involvement in glucose metabolism. Yan et al. (2014) have reported that reduced vaspin concentration is a causative element for diabetes among non-diabetes and the progression of T2DM among DM patients. ${ }^{26}$ The variable results reported the relationship between vaspin anthropometric and metabolic parameters such as negative, ${ }^{21}$ positive, ${ }^{22}$ and no significant association..$^{14}$

Our results regarding gender are similar to Chang et al. (2010), ${ }^{27}$ while dissimilar to a study that observed higher vaspin levels in females compared to males. ${ }^{28}$ We do not have any reason for no genderwise difference of serum vaspin level. Overall, our results support the idea of the involvement of serum vaspin in T2DM, and binary logistic regression analysis further reinforced its association with T2DM. The differences in the present study and other studies may be attributed to genetic factors, size of the research population, different dietary patterns and geographical locations, and the use of different kits.

No significant variation in serum ADN levels was noted in the DM subjects than in the control subjects. Serum ADN levels were higher in cases and control groups with $\mathrm{BMI}>25$, and no gender-wise change was noticed in ADN levels. Serum ADN levels were significantly correlated with few metabolic phenotypes in patients and the control group. We didn't find any remarkable change in serum ADN levels in the DM subjects compared to the healthy group. Simultaneously, researchers have reported lower, ${ }^{22}$ higher, ${ }^{29}$ and no change ${ }^{30}$ in serum ADN levels among T2DM patients compared to the healthy group. Similar to our results, no genderwise difference was reported by a Pakistani study. ${ }^{31}$ Possible reasons for the difference in ADN levels could be the participants' different genetic makeup and illness levels.

Limitations of the study: The smaller sample size is one of the limitations of this study. Moreover, being a cross-sectional study, no cause-and-effect conclusion be drawn.

\section{CONCLUSION}

The DM group displayed substantially lower serum vaspin and omentin-1 levels. However, there was no consistent relationship observed between these adipocytokines and metabolic phenotypes. Further multi-centered studies on a larger scale are needed to identify these adipocytokines' conclusive roles in $\mathrm{T} 2 \mathrm{DM}$.

Grant Support \& Financial Disclosures: "This work was supported by the Deanship of Scientific Research (DSR), King Abdulaziz University, Jeddah, under grant No. G-585-828-1438. The authors, therefore, acknowledge with thanks, DSR technical and financial support."

\section{REFERENCES}

1. World Health Organization. Global report on diabetes. 2016. Available at http://apps.who.int/iris/ bitstream/10665/204871/1/9789241565257_eng.pdf?ua=1 (Accessed on $10^{\text {th }}$ December 2016).

2. Al-Rubeaan K, Al-Manaa HA, Khoja TA, Ahmad NA, AlSharqawi AH, Siddiqui K, et al. Epidemiology of abnormal glucose metabolism in a country facing its epidemic: SAUDIDM study. J Diabetes. 2015;7:622-632. doi: 10.1111/17530407.12224

3. Lopez-Jaramillo P, Gomez-Arbelaez D, Lopez-Lopez J, Lopez-Lopez C, Martínez-Ortega J, Gomez-Rodriguez $\mathrm{A}$, et al. The role of leptin/adiponectin ratio in metabolic syndrome and diabetes. Horm Mol Biol Clin Investig. 2014;18:37-45.

4. Ruan H, Dong LQ. Adiponectin signaling and function in insulin target tissues. J Mol Cell Biol. 2016;8:101-109. doi: 10.1093/jmcb/mjw014

5. Heiker JT. Vaspin (serpinA12) in obesity, insulin resistance, and inflammation. J Pept Sci. 2014;20:299-306. doi: 10.1002/ psc. 2621

6. Youn BS, Kloting N, Kratzsch J, Lee N, Park JW, Song ES, et al. Serum vaspin concentrations in human obesity and type 2 diabetes. Diabetes. 2008;57:372-377.

7. Yan P, Liu D, Long M, Ren Y, Pang J, Li R. Changes of serum omentin levels and relationship between omentin and adiponectin concentrations in type 2 diabetes mellitus. Exp Clin Endocrinol Diabetes. 2011;119:257-263. doi: 10.1055/s0030-1269912

8. Baig M, Alghalayini KW, Gazzaz ZJ, Atta H. Association of Serum Omentin-1, Chemerin, and Leptin with Acute Myocardial Infarction and its Risk Factors. Pak J Med Sci. 2020;36:1183-1188. doi: 10.12669/pjms.36.6.2372

9. Gonzalez N, Moreno-Villegas Z, Gonzalez-Bris A, Egido J, Lorenzo Ó. Regulation of visceral and epicardial adipose tissue for preventing cardiovascular injuries associated to obesity and diabetes. Cardiovasc Diabetol. 2017;16:44.

10. Matthews DR, Hosker JP, Rudenski AS, Naylor BA, Treacher DF, Turner RC. Homeostasis model assessment: insulin resistance and beta-cell function from fasting plasma glucose and insulin concentrations in man. Diabetologia. 1985;28:412-419.

11. Habi AA, Sadeghi M, Arab A, Hajianfar H. The association between omentin and diabetes: a systematic review and meta-analysis of observational studies. Diabetes Metab Syndr Obes. 2019;12:1277. doi: 10.2147/DMSO.S206981 
12. Korany MA, Sonbol A, Elgouhary SM. Omentin-1 and diabetic retinopathy in type 2 diabetic patients. Alexandria J Med. 2018;54:323-326.

13. Alizadeh S, Mirzaei K, Mohammadi C, Keshavarz SA, Maghbooli Z. Circulating omentin-1 might be associated with metabolic health status in different phenotypes of body size. Arch Endocrin Metab. 2017;61:567-574. doi: 10.1590/2359-3997000000269

14. Rahimlou M, Mirzaei K, Keshavarz SA, Hossein-nezhad A. Association of circulating adipokines with metabolic dyslipidemia in obese versus non-obese individuals. Diabetes Metab Syndr: Clin Res Rev. 2016;10:S60-65.

15. Auguet T, Quintero Y, Riesco D, Morancho B, Terra X, Crescenti $A$, et al. New adipokines vaspin and omentin. Circulating levels and gene expression in adipose tissue from morbidly obese women. BMC Med Genet. 2011;12:6068. doi: 10.1186/1471-2350-12-60

16. Moreno-Navarrete JM, Catalan V, Ortega F, GomezAmbrosi J, Ricart W, Frühbeck G, et al. Circulating omentin concentration increases after weight loss. Nutr Metab. 2010;7:27-33.

17. Tan BK, Adya R, Randeva S. Omentin: a novel link between inflammation, diabesity, and cardiovascular disease. Trends Cardiovasc Med. 2010;20:143-148. doi: 10.1016/j. tcm.2010.12.002

18. Zhang Q, Zhu L, Zheng M, Fan C, Li Y, Zhang D, et al. Changes of serum omentin-1 levels in normal subjects, type 2 diabetes and type 2 diabetes with overweight and obesity in Chinese adults. Ann D'endocrinologie. 2014;75:171-175. doi: 10.1016/j.ando.2014.04.013

19. Pan HY, Guo L, Li Q. Changes of serum omentin-1 levels in normal subjects and in patients with impaired glucose regulation and with newly diagnosed and untreated type 2 diabetes. Diabetes Res Clin Pract. 2010;88:29-33. doi: 10.1016/j.diabres. 2010.01.013

20. Jian W, Peng W, Xiao S, Li H, Jin J, Qin L, et al. Role of serum vaspin in progression of type 2 diabetes: a 2-year cohort study. PLoS One. 2014;9:e94763. doi: 10.1371/journal. pone.0094763

21. Sathyaseelan AJ, Adole PS, Wyawahare M, Saya RP. Assessment of serum vaspin levels among type 2 diabetes mellitus patients with or without acute coronary syndrome. J Clin Diagn Res. 2016;10:BC07-BC10.

22. Montazerifar F, Karajibani M, Keikhaie MA, Mohammadi M, Jouy SH, Rezaie M. Serum Adiponectin and Vaspin levels in Abdominal Obesity and Type 2 Diabetes Mellitus. Iran J Diabetes Obes. 2018;10.
23. Bilir BE, Guldiken S, Tuncbilek N, Demir AM, Polat A. The effects of fat distribution and some adipokines on insulin resistance in subjects with prediabetes. Endokrynol Pol. 2016;67:277-282. doi: 10.5603/EP.a2016.0023

24. Feng R, Li Y, Wang C, Luo C, Liu L. Higher vaspin levels in subjects with obesity and type 2 diabetes mellitus: a metaanalysis. Diab Res Clin Pract. 2014;106:88-94.

25. Wada J. Vaspin: a novel serpin with insulin-sensitizing effects. Exp Opinon Investig Drugs. 2008;17:327-333.

26. Yan T, Li L, Wang H, Wang J, Cai D. Correlation between adipocytokines levels and metabolic syndrome in type 2 diabetes mellitus. J South Med Univ. 2014;34:275-278.

27. Chang HM, Park HS, Park CY, Song YS, Jang YJ. Association between serum vaspin concentrations and visceral adipose tissue in Korean subjects. Metabolism. 2010;59:1276-1281. doi: 10.1016/j.metabol.2009.11.021

28. Hida K, Poulsen P, Teshigawara S, Nilsson E, Friedrichsen $M$, Ribel-Madsen R, et al. Impact of circulating vaspin levels on metabolic variables in elderly twins. Diabetologia. 2012;55:530 -532. doi: 10.1007/s00125-011-2385-0

29. Hung WC, Wang CP, Lu LF, Yu TH, Chiu CA, Chung FM, et al. Circulating adiponectin level is associated with major adverse cardiovascular events in type 2 diabetic patients with coronary artery disease, Endocr J. 2010;57;793-802.

30. Al-Hamodi Z, Molham AH, Al-Meeri A, Saif-Ali R. Association of adipokines, leptin/adiponectin ratio and C-reactive protein with obesity and type 2 diabetes mellitus. Diabetol Metab Syndr. 2014;6:99. doi: 10.1186/1758-5996-6-99

31. Najam SS, Awan FR, Baig SM. Serum adiponectin levels in diabetes, obesity and gender in Punjabi subjects from Faisalabad, Pakistan. J Pak Med Assoc. 2014;64:1186-1188.

\section{Authors' Contribution:}

MB Conceived the idea, did practical work, drafted manuscript and responsible and accountable for the work's accuracy or integrity.

ZJG, MAB, SHZ Contributed to data collection and analysis, reviewed and edited manuscript. 